\title{
The state and consumer confidence in eco-labeling: organic labeling in Denmark, Sweden, The United Kingdom and The United States
}

\author{
Kim Mannemar Sønderskov • Carsten Daugbjerg
}

Accepted: 16 September 2010/Published online: 11 November 2010

(C) Springer Science+Business Media B.V. 2010

\begin{abstract}
Trustworthy eco-labels provide consumers with valuable information on environmentally friendly products and thus promote green consumerism. But what makes an eco-label trustworthy and what can government do to increase consumer confidence? The scant existing literature indicates that low governmental involvement increases confidence. This suggests that government should just provide the basic legal framework for eco-labeling and leave the rest to non-governmental organizations. However, the empirical underpinning of this conclusion is insufficient. This paper analyses consumer confidence in different organic food labeling regimes with varying degrees of governmental involvement. Using unique and detailed survey data from the US, United Kingdom, Denmark, and Sweden, the analysis shows that confidence is highest in countries with substantial state involvement. This suggests that governments can increase green consumerism through active and substantial involvement in eco-labeling.
\end{abstract}

Keywords Eco-labeling · Consumer confidence · Organic food · Ordered logistic regression

\section{Introduction}

The vision of a green economy, as articulated by political leaders on both sides of the Atlantic Ocean as well as in the literature on ecological modernization, relies on the assumption that consumers will actually demand climate

K. M. Sønderskov $(\bowtie) \cdot$ C. Daugbjerg

Department of Political Science, Aarhus University, Bartholins

Allé 7, 8000 Aarhus C, Denmark

e-mail: ks@ps.au.dk and environmentally friendly products (Mol and Spaargaren 2000; Seyfang 2005). However, at least three conditions must be met before green consumerism will become widespread. First, consumers must have a fairly high level of environmental awareness before they consciously start buying green products. Second, they must be willing to act pro-environmentally when making individual purchasing decisions, because green products are often more expensive than conventional products. Third, because of this price premium, consumers must also possess sufficient information to ensure them that a good claiming to be environmentally friendly actually fulfils this promise (Carter 2007, p. 232; Jordan et al. 2004, p. 163; Gertz 2005).

While the institutional and attitudinal requisites for increasing environmental awareness and motivating pro-environmental behavior have already been established in the literature (e.g., Inglehart 1997; Lubell 2002; Sønderskov 2008b), the question of credible information about products claiming to be produced in an environmentally friendly way is under-researched. This paper addresses this issue, focusing on what governments can do to advance the supply of credible information on green products and consequently advance green consumerism. Eco-labeling, the labeling of environmentally friendly products, has been recognized as an effective way to provide easily accessible information (Lohr 1998), but the extent to which eco-labels increase green consumption is highly dependent on their trustworthiness. Thus, a central question is how to ensure trustworthy labels, and in this study we explore to what extent government engagement in eco-labeling impacts on consumers' confidence in such schemes.

The issue of trustworthiness figures prominently in the literature on eco-labeling (e.g., Boström 2006a; Boström and Klintman 2008; Nilsson et al. 2004; Thøgersen 2000), 
but very little attention has been paid to actual consumer confidence in the labeling schemes. Existing studies are more concerned with analyzing the way labeling and standard setting processes, in particular inclusiveness, affect trust in the labeling scheme. Rather than establishing consumer confidence directly, these studies use stakeholder organizations' inclusiveness as an indicator for trust in the labeling scheme (e.g., Nilsson et al. 2004; Boström 2006b; Boström and Klintman 2008). Clearly, the involvement of stakeholder organizations is important in generating consumer confidence in labeling schemes, but consumers may also be affected by the labeling scheme itself and a number of other factors. Therefore there is a need to establish directly how consumer confidence is affected by various types of eco-labeling schemes. In relation to the discussion of the role of the state in the green economy a question of particular interest is how different degrees of governmental involvement in eco-labeling actually affect consumer confidence. A few studies have addressed consumer confidence and the role of government, but not in any detail (e.g., Boström and Klintman 2006). In studies by Gertz (2005) and by Ward et al. (2004) consumers were asked which type of certification and labeling body (governmental or private) they would trust most in handling an eco-labeling scheme. These analyses found that consumers preferred environmental or consumer organizations over governmental organizations. However, respondents were asked to choose between hypothetical alternatives that they had not necessarily experienced.

Thus, very little thorough research exists on how the design of eco-labeling schemes affects consumer confidence. This issue is crucial in designing schemes that have the potential to contribute to the emergence of a green economy. Hence, this study compares the level of consumer confidence in different existing schemes rather than hypothetical ones to generate insights into the factors that affect consumer confidence in eco-labeling. As our case, we compare confidence in organic food labels in Sweden, Denmark, the UK, and the US. These countries were chosen because they operate certification and labeling systems with varying degrees of governmental involvement. Based on a cross-national survey designed for this purpose, we explore how varying degrees of governmental involvement affect confidence, while controlling for several alternate explanations. In contrast to the few previous studies, our analysis shows that schemes relying on heavy governmental involvement attract more confidence than schemes with less state involvement.

The paper proceeds as follows: the following section reviews the sparse literature on the role of government in eco-labeling and discusses two alternate views on the effects of governmental involvement on consumer confidence. The subsequent empirical section outlines the organic labeling schemes in the four countries. The balance of the paper compares the level of consumer confidence, accounts for the research methods applied to establish the impact of government involvement on consumer confidence and undertakes a regression analysis to explain the observed cross-national pattern, considering a number of alternative explanations. The last section concludes and attempts to distil the lessons learned for policy makers.

\section{Theoretical considerations on third party verification and consumer confidence}

Green consumption is often associated with higher consumer prices and information asymmetry between producers, retailers, and consumers. In most cases, it is impossible to tell by appearance if a product has been produced in an environmentally friendly way, even after purchase. Producers and/or retailers who exploit the information asymmetry and provide false information about their products can increase profit and/or sell their products at a lower price than honest competitors. Without an institutional set-up that can guarantee to consumers that producers are complying with certain environmental production standards, prospective green consumers face a problem of adverse selection. Without credible and easily accessible information, supply of true environmentally friendly goods will be at lower levels than otherwise, which hampers green consumerism-as in Akerlof's classic example from the used car market (Akerlof 1970; Caswell and Mojduszka 1996).

Eco-labeling is a way to provide consumers with credible and easily accessible information on the environmental attributes of a product. Eco-labeling is based upon "standardization of principles and prescriptive criteria" (Boström and Klintman 2008, p. 28) for environmentally friendly products and serves the purpose of differentiating the product from other products and of ensuring consumers that a product is produced in accordance with the standards. Under eco-labeling schemes producers are usually, but not always, licensed by an independent third party that also audits whether producers comply with the standards laid down by the labeling scheme (Jordan et al. 2005, p. 482; Boström and Klintman 2008, p. 28). ${ }^{1}$ This third party can be a private organization or in some instances a state agency. State engagement in eco-labeling is most intensive where the state sets the standards, certifies products and producers, and very marginal when these

\footnotetext{
${ }^{1}$ However, there are also eco-labelling schemes with second and first party certification. The labelling scheme is organized by an industry association in the former and by the producer in the latter (Boström 2006a, p. 141).
} 
functions are left to private organizations. In the latter situation, the minimal role of the state is to recognize the label, or at least not reject it (see Hysing 2009). This recognition can, for instance, be demonstrated in the government's purchasing decisions. The state may also play a more indirect role as standard setter and authorizer of private certification and inspection bodies.

Some degree of state support is important for the broader legitimacy of labeling schemes and the trust of consumers, but it is not evident in the eco-labeling literature to what extent the state should become involved to optimize legitimacy and trust. This question links up with a broader discussion in the literature on environmental governance about the extent to which state involvement is required in the successful application of new environmental policy instruments (NEPIs), of which eco-labeling is one example. For instance Jordan et al. (2005) find that NEPIs are rarely applied without some sort of state involvement. Focusing on eco-labeling Boström (2006a, p. 153) shares this view, arguing that:

Any type of regulation and governance relies on legitimacy, but new regulatory arrangements that are built on non-state horizontal relationships have structural drawback. They cannot rely on traditional enforcement capacities and they have, by definition, cut themselves off from the political system of representative democracy which have long been assumed to be the ultimate source of policy- and rulemaking legitimacy and authority.

As for a fairly complicated issue like green production, people may be more inclined to trust information provided by government institutions than by private organizations. They may believe that the former possess higher expertise on the issue than the latter because information about environmental and public health issues is usually provided by government institutions. Further, a government labeling scheme is likely to have access to government financial resources to promote the label because failure is likely to affect the more general reputation of the agency administering the scheme. Though government can subsidize private labeling schemes, it is unlikely that they be financially privileged to the same extent. Accordingly, it has been suggested that the state's takeover of organic labeling in Denmark successfully increased consumer confidence (e.g., Hofer 2000).

However, there are factors pulling in the contrary direction, suggesting a minimal role for the state in ecolabeling. For instance, Boström and Klintman (2006) and Lilliston and Cummins (1998) argue that the involvement of the United States Department of Agriculture (USDA) may have watered down the US state organic standards and triggered skepticism within the organic movement.
Boström and Klintman (2006) compare the American statecentred scheme with the Swedish scheme and conclude that the Swedish scheme attracts more consumer confidence because of substantial involvement of non-governmental organizations in Sweden. However, they do not consider alternate explanations for the varying levels of consumer confidence. Gertz (2005) reports lower consumer confidence in government labels in Europe, while Ward et al. (2004) cannot find lower confidence in government labels among Americans (in Utah). Despite limited research on this matter, the sparse evidence seems to suggest that labeling should be handled by independent organizations rather than the state.

In sum, to establish the optimal role of the state in ecolabeling more research is needed and therefore this article explores the issue. Taking organic food labeling as an example, we analyze whether substantial state engagement in eco-labeling affects consumer confidence. At first sight, consumption of organic food may not be the most obvious example of green consumerism, because the environmental impact of organic farming is still debated (particularly outside Europe) and because consumers also buy organic produce for other reasons than environmental (health, quality, etc.). Nevertheless organic consumers face the same dilemma as other green consumers. Usually, organic foods are significantly more expensive than conventional foods and it is difficult for individual consumers to verify whether products claiming to be organic actually are organically grown; they cannot easily be distinguished from conventional foods by appearance and it is difficult for consumers to monitor the production process.

Governments have engaged differently in organic labeling systems are organized in various ways across countries. This makes organic labeling particularly well suited for exploring how the extent of government engagement impacts on consumer confidence. Hence, labeling of organic foods is an excellent case when exploring the impact of state involvement, and there are good reasons to believe that our finding would be relevant to other eco-labeling schemes.

\section{Organic labeling systems in four countries}

The United States, United Kingdom, Sweden, and Denmark apply different certification and labeling systems. We can distinguish among four different eco-labeling systems that vary significantly on three dimensions: the degree of state engagement, the number of certifiers, and the number of labels. In all four countries, governments have set baseline standards for organic, but private organic certifiers are allowed to apply higher standards as long as they comply with all baseline standards. In the three European countries, 
national standards must comply with EU standards. Though not similar, EU and US organic standards are not markedly different, which is indicated by the fact that approximately 18 EU based certification bodies are accredited by the US Department of Agriculture. Since 2002, the US certification and labeling system has relied on a number of private certifiers, but they must be accredited by the US Department of Agriculture. Certifiers license producers and their certification warrants the use of the USDA organic label, but other labels may also be used (Agricultural Marketing Service 2003: Subpart D). In the UK, the state is also the "certifier of the certifiers" and thus leaves certification and labeling to private bodies. But in contrast to the US scheme, no government label exists; each certifier has its own label. The Soil Association is the dominant certification body in the UK, certifying and labeling over $80 \%$ of all organic food being sold in the UK, but there are other labels as well (e.g., Organic Growers' Association and Organic Food Federation). In most cases, the private certifiers have stricter and/or additional requirements compared to government regulation (Department for Environment, Food, and Rural Affairs 2010). In Sweden the non-governmental KRAV label is very dominant, labeling approximate $95 \%$ of all food sold in Sweden (personal correspondence KRAV, August 2009). KRAV certification and inspection of producers, processors, and retailers is undertaken by four private certification bodies (KRAV 2010). KRAV is a state accredited label that complies with EU organic rules, but some KRAV's requirements are stricter than the EU rules. Organic farmers are not required to be KRAV certified to receive government subsidies for organic farming as long as they comply with the EU's rules for organic farming, but KRAV certification is needed to market produce as organic through commercial sales channels. In Denmark, the state operates the certification and labeling system. Imported foods can be labeled with other labels, but the state label is practically the sole national organic label and only state-certified farms are allowed to market organically labeled products and receive state support. Imported food labeled with foreign labels must comply with the EU's rules for organic farming (Fødevarestyrelsen 2010).

In sum, the Swedish scheme is run by a governmentauthorized private certifier, who has obtained nearmonopoly status with its own label and requirements. In the UK the situation is fairly similar. The Soil Association has been licensed to certify but has not obtained dominance on labeling to the same as extent as KRAV in Sweden. Though the Swedish and UK governments control who is authorized to certify, their role in certification is not directly visible to consumers. In the US government involvement in organic certification is more visible because a state label as been established which private certifiers can use. However, the state plays the largest role in Denmark, where it has a monopoly on certification and, in practice, on labeling. The labeling schemes are summarized in Table 1.

If heavy state involvement increases consumer confidence we would expect much higher consumer confidence in Denmark compared to the other countries. If, on the other hand, private certification attracts confidence, the opposite pattern should be observed. Besides the level of involvement, some scholars argue that the number of labels affects consumer confidence. Several labels create confusion and uncertainty, which erodes credibility (Hamm and Michelsen 1996; Environmental Protection Agency 1998, p. 55). If this is the case, the British scheme should attract the lowest level of confidence, while the other should be at par.

\section{Research design}

Obviously, other factors besides labeling scheme can affect confidence across countries. Cross-national differences may not be due to the labeling scheme at all, but instead to country-level variation in beliefs, attitudes, etc. For instance, the Danes and Swedes are among the most trusting people in the world (Delhey and Newton 2005; Hudson 2006; Sønderskov 2008a) and they have relatively high levels of environmental concern (Inglehart 1995). Thus to establish the extent to which state involvement affects consumer confidence, we need to control for other relevant factors. We analyze the level of label confidence in the four countries while holding a range of relevant alternative explanations constant using survey data from the COP-survey, a self-administered web survey with participants recruited from standing panels. It consists of representative samples (on various demographic parameters) of approximately 1,000 respondents from the UK, the US, Denmark, and Sweden and contains measures on confidence in organic labels as well as several possible control variables. ${ }^{2}$

Using these survey data, we regress label confidence on country of residence, while controlling for variations in beliefs, attitudes, etc. By controlling for these alternate explanations, the remaining partial effect of country of residence denotes the differences in confidence that can be ascribed to country-level differences in labeling schemes.

\footnotetext{
${ }^{2}$ Only respondents not living with their parents (or grandparents) are sampled to ensure that the respondents occasionally shop food. The response rate varies between 39 and 57\% across countries. Although this is rather low, there is no particular reason to expect sampling bias as non-responders did not know the topic before refusing to participate. The fieldwork was conducted by AC Nielsen and Survey Sampling International in April/May 2008. The codebook is available upon request.
} 
Table 1 Organic labeling schemes in Sweden, UK, US and Denmark

\begin{tabular}{|c|c|c|c|c|}
\hline & $\begin{array}{l}\text { The role of the state } \\
\text { in certification }\end{array}$ & Number of certifiers & $\begin{array}{l}\text { Effective number } \\
\text { of labels }\end{array}$ & $\begin{array}{l}\text { Level of state } \\
\text { involvement }\end{array}$ \\
\hline Sweden & $\begin{array}{l}\text { Certifies the private certifiers, but private } \\
\text { body has additional rules }\end{array}$ & 4 (certify for KRAV and EU) & 1 (KRAV) & Low \\
\hline $\begin{array}{l}\text { United } \\
\text { Kingdom }\end{array}$ & $\begin{array}{l}\text { Certifies the private certifiers, but private } \\
\text { bodies have additional rules }\end{array}$ & $\begin{array}{l}\text { Approx. } 10 \text { (but Soil } \\
\text { association dominates) }\end{array}$ & $\begin{array}{l}\text { Approx } 10 \text { (but SA's label } \\
\text { dominates) }\end{array}$ & Low \\
\hline USA & Certifies the private certifiers & Approx. 50 & State label dominates & Low-medium \\
\hline Denmark & Certifies producers directly & 1 (state) & 1 (state) & Very high \\
\hline
\end{tabular}

In order to estimate the partial level of confidence, all relevant explanations need to be included in the analysis. This is not straightforward, as, to our knowledge, no previous studies identify the individual level determinants of labeling confidence. This implies that a complete list of relevant explanations does not exist. Instead we will draw on the literature that deals with the determinants of trust in general and we will include other obvious explanations as well. Four types of explanations are included: social background variables, two forms of generalized trust, environmental values, and finally level of organic food consumption.

Gender, age, educational level, residential characteristics (rural vs. urban), country of origin (immigrant vs. native), and children in household are included as social background variables. Gender and age are standard controls and we have no expectations about their effect. ${ }^{3} \mathrm{We}$ expect that the lower educated and the rural population in general are more skeptical about public or private policy schemes which can be denoted centralist or elitist in nature. Education has also been found to affect trust in other people (but not always in governmental institutions), which also suggests a positive effect of education on confidence (Uslaner 2002: Chaps. 4-5; Hudson 2006). Likewise, we expect immigrants to have less trust in labels because of unfamiliarity with organic food and/or the specific labeling system. Immigrants (and other minorities) have also previously been found to have less trust in other people and institutions (Uslaner 2002, Chaps. 4-5). In regard to children in the household, families with children can be expected to be more concerned about pesticides and health issues than the average consumer, implying that they probably are more likely not only to consume more organic food but also to have more confidence in organic labeling. Note, however, that these background variables do not vary

\footnotetext{
3 Income is also a standard social background explanation. However, quite a few respondents did not reveal their income, which implies that including income will reduce the sample size. We have estimated models that include income and its effect is insignificant and does not change the effect of country of residence. Moreover, it is not obvious that income should affect confidence. On that basis we do not include income in the models reported below.
}

much at the country level (see Table 2). This implies that they probably do not explain cross-national variation in confidence, but for the sake of comprehensiveness we include them in the analysis.

The second type of variables, measures of trust as a generalized phenomenon, certainly varies between countries. Several studies have shown that Danes and Swedes are among the most trusting people in the world, having high levels of trust in other people and, more importantly, in institutions like courts and the government (cf. above). This is also the case in our data (see Table 2). This generalized confidence may very well spill over into confidence in labels. We include two measures of such generalized confidence: generalized social trust and generalized institutional trust. Generalized social trust is the belief that most people are trustworthy. While we do not expect trust in other people to affect trust in labels per se, we include it to capture people's basic propensity to trust and their general level of optimism (Uslaner 2002), which very well may affect label confidence. Furthermore, social trust is also related to beliefs about safetyness of food in

Table 2 Descriptive statistics for independent variables, total and by country

\begin{tabular}{lllllll}
\hline & \multicolumn{3}{l}{ Share/mean } & & & \\
\cline { 2 - 7 } & \multicolumn{2}{l}{ Total } & Denmark & Sweden & UK & US \\
\hline Gender (female) & 0.52 & 0.52 & 0.52 & 0.51 & 0.52 \\
Age & 45 & 45 & 43 & 46 & 46 \\
Educational level & 0.63 & 0.63 & 0.69 & 0.62 & 0.75 \\
Residential area (town/city) & 0.68 & 0.69 & 0.76 & 0.63 & 0.65 \\
Native to country (yes) & 0.94 & 0.96 & 0.94 & 0.91 & 0.93 \\
Children living at home (yes) & 0.39 & 0.37 & 0.42 & 0.37 & 0.39 \\
Generalized institutional trust & 0.53 & 0.68 & 0.51 & 0.42 & 0.47 \\
Generalized social trust & 0.58 & 0.68 & 0.59 & 0.51 & 0.52 \\
Environmental values & & & & & \\
Materialist & 0.32 & 0.18 & 0.16 & 0.47 & 0.51 \\
Mixed & 0.57 & 0.69 & 0.68 & 0.47 & 0.43 \\
Postmaterialist & 0.11 & 0.13 & 0.16 & 0.06 & 0.06 \\
Organic consumption & 0.29 & 0.35 & 0.27 & 0.26 & 0.26 \\
\hline
\end{tabular}

Source COP survey 
general (Kjærnes et al. 2007, p. 84). Generalized institutional trust, on the other hand, is expected to affect labeling trust directly. It reflects people's trust in the formal institutions and rules that regulate their lives. Moreover, generalized institutional trust is strongly affected by corruption (Uslaner 2008). Both corruption and low trust in institutions in general are very likely to affect trust in ecolabeling schemes.

The third type of variables included is environmental awareness, measured with postmaterial value orientation (cf. Inglehart 1997). People who hold green attitudes are probably more likely to have positive opinions about ecolabels.

The final variable is a measure of organic food consumption. While the causality most likely solely goes from trust to consumption, it could be that heavy consumers of organic food in part choose to trust labels to legitimize their decisions (Sønderskov 2009). Previous studies show that Danes on average consume far more organic foods than residents in the other countries (Daugbjerg and Sønderskov, forthcoming; Sønderskov 2009; see also Table 2). To rule out the possibility that cross-national differences are caused by differences in consumption, we estimate a model that includes level of consumption as predictor. Descriptive statistics for all variables are reported in Table 2, and details on wording and/or coding for each independent variable are found in Table 3. All independent variables, except for age, are scaled from 0 to 1 to make it (somewhat) easier to compare effects.

To measure the dependent variable, labeling confidence, the respondents were given the following statement: "You can trust that products marketed as organic actually are organic in the majority of cases" and asked to evaluate it on a 5-point Likert scale from "completely disagree" to "completely agree.

\section{Explaining variation in consumer confidence}

The first evidence on the effect of state involvement in organic labeling system is found in Table 4, which shows consumer confidence in products claiming to be organic.

Before going into the cross-country differences, it is worth noticing that the level of confidence in organic labels is quite high. More than $50 \%$ of the respondents agree or completely agree that organic labels are trustworthy in each country. Apparently, a majority of consumers possess at least one of the prerequisites for green consumerism, but there are noteworthy cross-country differences. This indicates that some labeling schemes appear more trustworthy than others and that there is room for improvements in some countries. Far more people in Denmark agree completely with the statement than people in the other countries. In fact, Danes express a significantly higher degree of

Table 3 Measurement of the independent variables

\begin{tabular}{|c|c|}
\hline Variable & Details \\
\hline Country of residence & Denmark, Sweden, UK, US \\
\hline Gender & Dummy variable; $1=$ female \\
\hline Age & Age in years \\
\hline Education & Originally 9-12 ordered categories depending on country*; Rescaled $0-1 ; 1=$ Highly educated \\
\hline Residential area & Dummy; $1=$ respondent is living in a city of more than 50,000 inhabitants \\
\hline Country of origin & Dummy; 1 = Native \\
\hline Children in household & Dummy; $1=$ one or more children (under age 20 ) living in household \\
\hline $\begin{array}{l}\text { Generalized institutional } \\
\text { trust }\end{array}$ & $\begin{array}{l}\text { Scale based on five items: "How much do you personally trust each of the following institutions?: the legal system, } \\
\text { Congress**, the police, the civil services, the government." All answers on 11-point scales; the final scale is rescaled } \\
\text { from } 0 \text { to } 1 ; 1=\text { high trust. Cronbach's alpha }=0.90\end{array}$ \\
\hline Generalized social trust & $\begin{array}{l}\text { Scale based on three items: "Generally speaking, would you say that most people can be trusted, or that you can't be } \\
\text { too careful in dealing with people?"; "Do you think that most people would try to take advantage of you if they got } \\
\text { the chance, or would they try to be fair?"; "Would you say that most of the time people try to be helpful or that they } \\
\text { are mostly looking out for themselves?" All answers on 11-point scales. The final scale is rescaled from } 0 \text { to } 1 \text {; } \\
1=\text { high trust. Cronbach's alpha }=0.84\end{array}$ \\
\hline Environmental values & $\begin{array}{l}\text { Three categories: Materialist, mixed, postmaterialist. Based on the four item postmaterialism battery (Inglehart 1997, } \\
\text { Ch. 4); Postmaterialist = strong environmental values }\end{array}$ \\
\hline Organic consumption & $\begin{array}{l}\text { Index based on three items: "Think about your shopping in the past } 6 \text { months: How large a share of your consumption } \\
\text { has been organic within the following food groups? Dairy products; Fruit and vegetables; Meat." All answers on 5- } \\
\text { point scales. The final index is rescaled from } 0 \text { to } 1 ; 1=\text { high consumption. }\end{array}$ \\
\hline
\end{tabular}

* The categories are the same as in the General Social Survey (US), European Social Survey (DK+SE), and European Values Study (UK)

** The wording varies between countries but is equivalent; the codebook is available on request 
Table 4 Trust in organic food labeling in Denmark, Sweden, UK, and US

\begin{tabular}{|c|c|c|c|c|c|}
\hline $\begin{array}{l}\text { You can trust that products marketed as organic actually are } \\
\text { organic in the majority of cases }\end{array}$ & Denmark (\%) & Sweden $(\%)$ & UK (\%) & US $(\%)$ & Total $(\%)$ \\
\hline Completely disagree & 2.0 & 3.7 & 4.5 & 5.0 & 3.8 \\
\hline Disagree & 7.9 & 17.9 & 15.9 & 17.4 & 14.8 \\
\hline Neither agree nor disagree & 8.5 & 20.0 & 25.2 & 23.3 & 19.2 \\
\hline Agree & 45.9 & 43.7 & 43.2 & 45.1 & 44.5 \\
\hline Completely agree & 35.7 & 14.7 & 11.2 & 9.3 & 17.8 \\
\hline Total & 100.0 & 100.0 & 100.0 & 100.0 & 100.0 \\
\hline $\mathrm{N}$ & 973 & 971 & 985 & 929 & 3,858 \\
\hline
\end{tabular}

Source COP survey

confidence compared to residents in all the other countries, while Swedes express slightly more confidence than the Americans and the British (cf. Model I in Table 5 below). Apparently, the Danish system attracts confidence, which supports a state-centred approach to eco-labeling; Denmark has by far the largest level of state involvement and also the highest level of confidence.

However, before jumping to conclusions and advising policymakers to impose state controlled eco-labeling around the world, two issues must be addressed. First, the picture is not crystal clear. The Swedish system comes in second in regard to confidence, and the Swedish labeling scheme, together with the British, is the least state controlled system in our analysis. Thus, the superiority of the state labeling system is not clear cut. Second, the crossnational differences might not be due to the labeling scheme at all, but rather to country-level variation in beliefs, attitudes, etc. Perhaps, the higher confidence among Nordic residents is simply a result of for example of higher environmental awareness or generalized trust, while the level of state involvement may not affect confidence. We address these concerns through further analysis of alternate explanations.

The analysis is conducted using an ordered logistic regression because our measure of labeling confidence only has five ordered categories and therefore cannot be assumed to be metric. The ordered logistic regression is superior to OLS in such situations. It treats the observed ordinal variable as a manifestation of a continuous, but unobserved, underlying variable. Labeling confidence is most likely continuous. Thus, a person's true level of confidence is unobserved, but it is assumed that this level affects her value on the observed ordinal variable. Although superior, interpretation is a bit more cumbersome in the ordered model. Sign, $t$, and $P$ values have the same meaning as in OLS, and the obtained coefficients also signify the effect of a 1-unit increase in the independent variables on the dependent variable. However, since the scale of the dependent variable is unobserved and hence unknown, the interpretation of the size of the coefficient is not straightforward. To ease interpretation, the predicted probability of answering "agree" or "completely agree" on the observed ordered dependent variable is reported for each country in addition to the coefficient. Obviously, the predicted probability is affected by the level of the other variables in the model. The calculation of the predicted probability is performed by setting the control variables to either their mean or to the most prevailing category.

The results of the analysis are shown in Tables 5 and 6 . Model I in Table 5 corresponds to Table 4 above as it only includes country of residence. Danish consumers are chosen as reference since the Danish labeling system is by far the most state-centric. The coefficients and their $t$ values show that Swedish, British, and US consumers express significantly lower levels of confidence than Danes. The predicted probabilities in the second column tell the same story; Danes are much more likely to express confidence. Since Danish consumers are the reference category, the results do not show if differences exist between consumers of the other countries. Calculations show that Swedes have significantly more confidence than both the British $(P<0.1)$ and the Americans $(P<0.05)$. There is no significant difference between British and American citizens (cf. notes to Table 5).

The following models include the four types of individual level explanations in sequence (according to their presumed causal order) to disclose which, if any, types of explanations explain the pattern in Model I. Although it is not the main focus of the analysis, this procedure also provides information on the determinants of labeling confidence. The social background variables are included in Model II. The overall picture does not change much when controlling for social background. This was expected because the social background variables do not vary much across countries. Danish consumers still have far more confidence than consumers in the other countries. However, Swedes are no longer more confident than the British, and the Americans have only slightly less confidence than 
Table 5 Predicting label confidence (ordered logit model)

\begin{tabular}{|c|c|c|c|c|c|c|}
\hline & \multicolumn{2}{|l|}{ Model I } & \multicolumn{2}{|l|}{ Model II } & \multicolumn{2}{|l|}{ Model III } \\
\hline & $\begin{array}{l}\text { Coefficient } \\
\text { (b) }\end{array}$ & $\begin{array}{l}\text { P agree/ } \\
\text { compl. agree }\end{array}$ & Coefficient (b) & $\begin{array}{l}\text { P agree/ } \\
\text { compl. agree }\end{array}$ & $\begin{array}{l}\text { Coefficient } \\
\text { (b) }\end{array}$ & $\begin{array}{l}\mathrm{P} \text { agree/ } \\
\text { compl. agree }\end{array}$ \\
\hline \multicolumn{7}{|l|}{ Country of residence } \\
\hline Denmark & Reference & 0.83 & Reference & 0.85 & Reference & 0.80 \\
\hline Sweden & $-1.20 * * *(-13.68)$ & 0.59 & $-1.28 * * *(-14.29)$ & 0.62 & $-0.88 * * *(-9.44)$ & 0.63 \\
\hline UK & $-1.35 * * *(-15.43)$ & 0.55 & $-1.27 * * *(-14.04)$ & 0.62 & $-0.65 * * *(-6.53)$ & 0.68 \\
\hline US & $-1.41 * * *(-15.96)$ & 0.54 & $-1.43 * * *(-15.70)$ & 0.58 & $-0.85 * * *(-8.62)$ & 0.63 \\
\hline Gender (female) & & & $0.29 * * *(4.71)$ & (female) & $0.27 * * *(4.42)$ & (female) \\
\hline Age & & & $-0.02 * * *(-7.48)$ & $(45)$ & $-0.02 * * *(9.46)$ & $(45)$ \\
\hline Education & & & $0.29 * *(2.50)$ & $(0.66)$ & $0.00(0.17)$ & $(0.66)$ \\
\hline Residential area (town/city) & & & $0.15^{*}(2.25)$ & (town/city) & $0.11 *(1.66)$ & (town/city) \\
\hline Country of origin (Native) & & & $0.09(0.72)$ & (yes) & $0.14(1.04)$ & (yes) \\
\hline Children in household (yes) & & & $0.04(0.63)$ & (no) & $0.01(0.17)$ & (no) \\
\hline Generalized institutional trust & & & & & $1.79 * * *(9.75)$ & $(0.53)$ \\
\hline Generalized social trust & & & & & $1.28 * * *(7.12)$ & $(0.58)$ \\
\hline $\mathrm{N}$ & & 3,858 & & 3,701 & & 3,677 \\
\hline McKelvey and Zavoina's $\mathrm{R}^{2}$ & & 0.09 & & 0.12 & & 0.18 \\
\hline
\end{tabular}

The coefficient for Sweden is significantly higher than UK $(P<0.1)$ and US $(P<0.05)$ in Model I; the coefficient is significantly lower for US than Sweden and UK $(P<0.1)$ in Model II; the coefficient for UK is significantly higher than US $(P<0.05)$ and Sweden $(P<0.01)$ in Model III

$\mathrm{b}=$ logit coefficient ( $t$ values in parentheses); P agree/compl. agree is the predicted probability of answering "agree" or "completely agree" in each country holding other variables at the value specified in parentheses

$* P<0.1$; ** $P<0.05$; *** $P<0.01$ (two-sided)

British and Swedes. Apparently, the higher level of confidence among Swedes is not caused by the labeling scheme, but rather by differences in social background. The predicted probabilities change somewhat in this model, but mainly because they are now calculated for a middle-aged native female, etc. (cf. values in parentheses).

Model III includes the measures of generalized trust. Both institutional and social trust have a large impact on confidence. Such generalized trust apparently spills over into trust in specific phenomena like eco-labels. The inclusion of the trust measures reduces the differences in confidence between Danes and residents of the other countries, as indicated by the smaller coefficients. Nevertheless, Danish consumers still exhibit significantly more confidence than those of the other countries. Interestingly, after taking differences in generalized forms of trust into account, the order of the remaining countries changes. UK consumers have significantly more confidence in organic labels than Swedes and Americans when trust is held constant. Again, this tells us that the relative success of the Swedish system has nothing to do with the labeling system itself, but instead is caused by high levels of trust within the Swedish population. We will return to this issue below.

The inclusion of environmental values in Model IV does not change the picture that emerged in Model III. Although people with postmaterial values have more confidence in labels, as expected, the cross-national pattern does not change. The final model includes self-reported level of organic food consumption. As noted above, the direction of causality is most likely or predominantly from confidence to consumption, and not the other way as assumed in Model V. Thus, we should not put too much confidence in the exact coefficients from this model. Nevertheless, it shows that even if consumption affects confidence, then Danish consumers-all else being equal-still have significantly higher confidence. Hence, the higher confidence in the Danish label is not just an effect of higher consumption.

In sum, the five models substantiate the pattern already found in Table 4, but it also reveals interesting new knowledge. Like in Table 4, Danish consumers exhibit a great deal more confidence in organic food labels than consumers in the other countries in all models. Although the difference decreases a bit when controlling for individual level explanations, the difference is highly significant and non-trivial. The predicted probability of expressing confidence is no less than 0.1 higher for Danish consumers in any model-and it is higher in most cases. This tells us that the higher level of confidence in Denmark is not solely caused by the fact that Danes are more trusting 
Table 6 Predicting label confidence (ordered logit model)

\begin{tabular}{|c|c|c|c|c|}
\hline & \multicolumn{2}{|l|}{ Model IV } & \multicolumn{2}{|l|}{ Model V } \\
\hline & Coefficient (b) & $\mathrm{P}$ agree/compl. agree & Coefficient (b) & $\mathrm{P}$ agree/compl. agree \\
\hline \multicolumn{5}{|l|}{ Country of residence } \\
\hline Denmark & Reference & 0.80 & Reference & 0.77 \\
\hline Sweden & $-0.88 * * *(-9.24)$ & 0.62 & $-0.78 * * *(-8.01)$ & 0.61 \\
\hline UK & $-0.68 * * *(-5.69)$ & 0.68 & $-0.49 * * *(-4.60)$ & 0.67 \\
\hline US & $-0.79 * * *(-7.73)$ & 0.64 & $-0.66 * * *(-6.09)$ & 0.64 \\
\hline Gender (female) & $0.29 * * *(4.56)$ & (female) & $0.28 * * *(4.42)$ & (female) \\
\hline Age & $-0.02 * * *(-9.58)$ & $(45)$ & $-0.03 * * *(9.84)$ & $(45)$ \\
\hline Educational level & $-0.24(0,34)$ & $(0.66)$ & $-0.12(-0.82)$ & $(0.66)$ \\
\hline Residential area (town/city) & $0.11 *(1.68)$ & (town/city) & $0.07(1.05)$ & (town/city) \\
\hline Native to country (yes) & $0.16(1.20)$ & (yes) & $0.28 * *(2.04)$ & (yes) \\
\hline Children living at home (yes) & $0.00(0.04)$ & (no) & $0.01(0.16)$ & (no) \\
\hline Generalized institutional trust & $1.85 * * *(9.91)$ & $(0.53)$ & $1.89 * * *(9.66)$ & $(0.53)$ \\
\hline Generalized social trust & $1.21 * * *(6.61)$ & $(0.58)$ & $1.16^{* * *}(6.09)$ & $(0.58)$ \\
\hline Environmental values & & (Mixed) & & (Mixed) \\
\hline Materialist & Reference & & Reference & \\
\hline Mixed & $0.09(1.28)$ & & $0.05(0.70)$ & \\
\hline Postmaterialist & $0.46 * * *(3.96)$ & & $0.32 * * *(2.64)$ & \\
\hline Organic consumption & & & $1.28 * * *(10.92)$ & $(0.29)$ \\
\hline $\mathrm{N}$ & & 3,604 & & 3,353 \\
\hline McKelvey and Zavoina's $\mathrm{R}^{2}$ & & 0.18 & & 0.21 \\
\hline
\end{tabular}

The coefficient for UK is significantly higher than Sweden and US $(P<0.01)$ in Model IV; The coefficient is significantly higher for UK than US $(P<0.1)$ and Sweden $(P<0.01)$ in Model V

$\mathrm{b}=$ logit coefficient ( $t$ values in parentheses); $P$ agree/compl. agree is the predicted probability of answering "agree" or "completely agree" in each country holding other variables at the value specified in parentheses

* $P<0.1$; ** $P<0.05$; *** $P<0.01$ (two-sided)

in general, nor is it a result of higher levels of environmental awareness, but a consequence of the state labeling system. This finding clearly supports the position that significant state engagement in eco-labeling has an independent positive effect on confidence.

Nevertheless, the evidence in support of a state labeling scheme is not clear-cut in our analysis. With its state label, the US scheme is slightly more state centred than the British and Swedish labeling schemes but Americans do not significantly surpass the Swedes and actually have less confidence than the British. We can dismiss that this has anything to do with the number of labels. According to this explanation, we should expect to find the lowest level of confidence in the UK, but this is clearly not the case. Another explanation could be that state labeling does not affect confidence and that the results are caused by an unobserved variable. A more plausible explanation is that the US labeling scheme was introduced recently, and that it takes a while before consumers get accustomed to a new scheme. An important factor that potentially may have impacted negatively on the confidence of consumers-at least in the short term-is that the political process in which the US organic standards were agreed was contested (Boström and Klintman 2006; Lilliston and Cummins 1998). We do not have the data to verify this speculation, but if true it can very well explain the unexpected difference between the British and the American scheme. In sum, despite of the unexpected difference between the British and the American citizens, our analysis suggests that substantial state involvement increases confidence.

In addition to this finding, other interesting findings pop out of the models. By far, the two most important additional predictors of label confidence are generalized social trust and especially generalized institutional trust. To explore the role of institutional trust further, we have reestimated Model IV in each country (omitting the country variables; estimates not shown, available on request). It could be that institutional trust only affects labeling confidence in countries relying on heavy state involvement. This is not the case, however; the effect of institutional trust is highly influential, significant, and about the same in all countries. Hence, people's perceptions of the formal 
institutions also affect their perception of non-state institutions like labeling systems provided by private parties.

Before moving on to discuss the implications of these findings, we will dwell briefly on the effects of the other variables. Since this study is the first to explore the individual level determinants of labeling confidence, the results deserve a few comments. Females and younger people express more confidence. Education also has some effect, although it disappears in Model III and onwards. Most likely, the effect of education is mediated by both types of generalized trust and environmental values. The urban population is slightly more confident, while immigrants do not hold lower confidence (except for in the final, but less valid model). People with high levels of environmental awareness hold more confidence, as signified by the positive effect of postmaterial values. The same thing goes for people with large consumption of organic foods, although the latter result is uncertain due to simultaneity bias.

\section{Conclusions}

Green consumerism requires that the consumers can identify true environmentally friendly goods, which can be obtained through reliable eco-labeling. This article has investigated the optimal role for governments who wish to enhance green consumerism.

Taking labeling of organic foods as our empirical case, the analyses compared the level of consumer confidence in existing organic labeling schemes. The analyses showed that substantial state involvement increases consumer confidence. The results suggest that governments who wish to promote green consumerism should engage heavily in eco-labeling. Apparently, consumers are more likely to trust labeling schemes where the state plays an active and visible role. Although this finding is at odds with extant results, our conclusion rests on fairly solid empirical evidence. Our study is the first of its kind to use cross-national data that contains measures of confidence in existing schemes and the first to control for alternate explanations.

Other factors were also found to affect consumer confidence. Citizens who have confidence in governmental institutions also have confidence in the labeling scheme. Importantly, this finding also applies to citizens in countries that do not rely on state labeling. This implies that countries, where citizens do not trust state institutions, cannot increase labeling confidence by relying on non-state labels. Most likely, the low level of institutional trust will affect the perception of private labels as well. This suggests that delegation of eco-labeling to private bodies is no easy fix to problems of low institutional trust, only the formidable task of improving citizens' trust in state institutions will do the job. Another pathway to increasing consumer confidence in eco-labeling goes through education and increased environmental awareness. Nor is this an easy fix, but perhaps a more achievable strategy than attempting to increase trust in state institutions.

Our results rest on data from four countries in one field of eco-labeling. Whether or not these findings can be generalized to other countries and products, is obviously an empirical question. Moreover, the study cannot predict the consequences of abandoning one type of scheme and switching to a state centred scheme. It could take several years before confidence passes its pre-existing level. The unexpected underperformance of the American scheme, which rests on moderate state involvement, may indicate that it takes a while before state labeling takes effect, in particularly if the process in which the standards were agreed was contested. Therefore, not only the design of the eco-labeling matters, but presumably also the way in which the design was brought about. Research by Boström and Klintman (2006) suggests that stakeholder inclusiveness and genuine consensus building are also important factors in generating trust in eco-labeling schemes.

Our findings also suggest the state has a role to play in eco-labeling. This questions a key aspect of the literature on ecological modernization which suggests that assigning responsibility for environmental governance to industry would lead to better environmental performance because it results in cooperative behavior and trust within industry. Our analysis demonstrates that even where a high degree of trust exists among stakeholders, as in the Swedish organic sector, consumer confidence is not markedly higher than where mistrust exists, as in the US organic sector (Boström and Klintman 2006) and does not even come close to the high level in Denmark where the state is sole organic certifier. Thus, there is ground for reconsidering the role of government in greening the economy. As suggested by MacKendrick (2005, p. 41) state leadership may be may be needed in all forms of environmental improvement.

Acknowledgments The authors are grateful to Andrew Jordan, two anonymous reviewers of this journal, and participants at the 60th Annual Conference of the Political Studies Association for constructive suggestions. The financial support of ICROFS (DARCOF III) is appreciated.

\section{References}

Agricultural Marketing Service. 2003. National organic program. Washington, DC: US Department of agriculture. http://www. ams.usda.gov/AMSv1.0/ams.fetchTemplateData.do?template $=$ TemplateF\&navID=RegulationsNOPNationalOrganicProgram Home\&rightNav1=RegulationsNOPNationalOrganicProgram Home \& topNav $=\& l$ eftNav $=$ NationalOrganicProgram\&page $=$ NOPRegulations\&resultType $=\&$ acct $=$ noprulemaking. Accessed 26 Jan 2010 
Akerlof, G.A. 1970. The market for "lemons": Quality uncertainty and the market mechanism. Quarterly Journal of Economics 84(3): 488-500.

Boström, M. 2006a. Establishing credibility: Practising standardsetting ideals in a Swedish seafood-labelling case. Journal of Environmental Policy and Planning 8(2): 135-158.

Boström, M. 2006b. Regulatory credibility and authority through inclusiveness: Standardization organizations in cases of ecolabelling. Organization 13(3): 345-367.

Boström, M., and M. Klintman. 2006. State-centered versus nonstatedriven organic food standardization: A comparison of the US and Sweden. Agriculture and Human Values 23(2): 163-180.

Boström, M., and M. Klintman. 2008. Eco-standards, product labeling, and green consumerism. New York, NY: Palgrave Macmillan.

Carter, N. 2007. The politics of the environment: Ideas, activism, policy, 2nd ed. Cambridge, UK: Cambridge University Press.

Caswell J.A., and E.M. Mojduszka. 1996. Using informational labeling to influence the market for quality in food products. American Journal of Agricultural Economics 78(Proceedings): $1248-1253$.

Daugbjerg, C., and K.M. Sønderskov. Forthcoming. Environmental policy performance revisited: Designing effective policies for green markets. Political Studies.

Delhey, J., and K. Newton. 2005. Predicting cross-national levels of social trust: Global pattern or Nordic exceptionalism? European Sociological Review 21(4): 311-327.

Department for Environment Food and Rural Affairs. 2010. Farming: Organic farming. http://www.defra.gov.uk/foodfarm/growing/ organic/index.htm. Accessed 26 Jan 2010.

Environmental Protection Agency. 1998. Environmental labeling issues, policies, and practices worldwide. Washington, DC: Environmental Protection Agency.

Fødevarestyrelsen. 2010. Økologiske Fødevarer. http://www. foedevarestyrelsen.dk/fdir/Pub/2006213/rapport.pdf. Accessed 2 Feb 2010.

Gertz, R. 2005. Eco-labelling: A case for deregulation? Law, Probability and Risk 4(3): 127-141.

Hamm, U., and J. Michelsen. 1996. Organic agriculture in a market economy: Perspectives from Germany and Denmark. In Fundamentals of organic farming, proceedings of the 11th IFOM conference, ed. T. Østergaard, 208-222. Tholey Theley: Ökozentrum Innsbach.

Hofer, K. 2000. Labelling of organic food products. In The voluntary approach to environmental policy: Joint environmental policymaking in Europe, ed. A. Mol, V. Lauber, and D. Liefferink, 156-191. Oxford, UK: Oxford University Press.

Hudson, J. 2006. Institutional trust and subjective well-being across the EU. Kyklos 59(1): 43-62.

Hysing, E. 2009. Governing without government? The private governance of forest certification in Sweden. Public Administration 87(2): 312-326.

Inglehart, R. 1995. Public support for environmental protection: Objective problems and subjective values in 43 societies. PS: Political Science and Politics 28(1): 57-72.

Inglehart, R. 1997. Modernization and postmodernization. Princeton, N.J: Princeton University Press.

Jordan, A., R.K.W. Wurzel, and L. Brückner. 2004. Consumer responsibility-taking and eco-labelling schemes in Europe. In Politics, products, and markets: Exploring political consumerism past and present, ed. M. Micheletti, A. Follesdal, and D. Stolle, 161-180. New Brunswick: Transaction Publishers.

Jordan, A., R.K.W. Wurzel, and A. Zito. 2005. The rise of "new" policy instruments in comparative perspective: Has governance eclipsed government? Political Studies 53(3): 477-496.
Kjærnes, U., M. Harvey, and A. Warde. 2007. Trust in food. New York: Palgrave.

KRAV. 2010. Certificeringer. http://www.krav.se/Foretag/Certifieringar/. Accessed 2 Feb 2010.

Lilliston, B., and R. Cummins. 1998. Organic versus "organic": The corruption of a label. The Ecologist 28(4): 195-201.

Lohr, L. 1998. Implications of organic certification for market structure and trade. American Journal of Agricultural Economics 80(5): 1125-1129. Proceedings Issue.

Lubell, M. 2002. Environmental activism as collective action. Environment and Behavior 34(4): 431-454.

Mackendrick, N.A. 2005. The role of the state in voluntary environmental reform: A case study of public land. Policy Sciences 38(1): 21-44.

Mol, A.J., and G. Spaargaren. 2000. Ecological modernization theory in debate: A review. Environmental Politics 9(1): 17-49.

Nilsson, H., B. Tunçer, and A. Thidell. 2004. The use of eco-labeling like initiatives on food products to promote quality assuranceis there enough credibility? Journal of Cleaner Production 12(5): 517-526.

Seyfang, G. 2005. Shopping for sustainability: Can sustainable consumption promote ecological citizenship? Environmental Politics 14(2): 290-306.

Sønderskov, K.M. 2008a. Environmental group membership, collective action, and generalized trust. Environmental Politics 17(1): 78-94.

Sønderskov, K.M. 2008b. Making cooperation work: Generalized social trust and large- $n$ collective action. Aarhus: Politica.

Sønderskov, K.M. 2009. Different goods, different effects: Exploring the effects of generalized social trust in large- $\mathrm{N}$ collective action. Public Choice 140(1): 145-160.

Thøgersen, J. 2000. Psychological determinants of paying attention to eco-labels in purchase decisions: Model development and multinational validation. Journal of Consumer Policy 23(3): 285-313.

Uslaner, E.M. 2002. The moral foundations of trust. Cambridge: Cambridge University Press.

Uslaner, E.M. 2008. Corruption, inequality, and the rule of law: The bulging pocket makes the easy life. New York: Cambridge University Press.

Ward, R., L. Hunnicutt, and J. Keith. 2004. If you can't trust the farmer, who can you trust? The effect of certification types on purchases of organic produce. International Food and Agribusiness Management Review 7(1): 60-77.

\section{Author Biographies}

Kim Mannemar Sønderskov is an assistant professor in Political Science at Aarhus University. His research focuses on environmental policy as well as causes and effects of social trust.

Carsten Daugbjerg is a professor at the Department of Political Science, Aarhus University, and currently Visiting Fellow at the Political Science Program, Research School of Social Sciences, The Australian National University. His fields of research are agricultural policy reform, the farm trade negotiations in the WTO, private food standard regulation in global trade, government interest group relations, and environmental policy. Currently, he directs a research project on comparative organic farming policy. He has published widely on these issues in international journals and has had four books published. 